\title{
Evaluation of acid base status and outcome of neonatal respiratory distress
}

\author{
Chaudhary GS ${ }^{1}$, KumarV ${ }^{2}$, Chaurasiya $\mathrm{O} \mathrm{S}^{3}$, Singh $\mathrm{M}^{4}$ \\ ${ }^{1}$ Dr Ghanshyam Chaudhary, Associate Professor, Department of Paediatrics, MLB Medical College Jhansi, UP, India, \\ ${ }^{2}$ Dr Vipin,Kumar, JR III, Department of Pediatrics, MLB Medical College Jhansi, Uttar Pradesh, India, ${ }^{3}$ Dr Om Shankar \\ Chaurasiya, MD (Paediatrics), Assistant Professor, Department of Paediatrics, MLB Medical College Jhansi, Uttar \\ Pradesh, India, ${ }^{4}$ Dr Mayank Singh, MD (Pathology), Assistant professor, Department of Pathology, MLB Medical \\ College Jhansi, Uttar Pradesh, India.
}

Address for correspondence: Dr Ghanshyam Chaudhary, MD (Paediatrics), Associate Professor, Department of Paediatrics, MLB Medical College Jhansi, UP, India. Email: drgschaudhary@rediffmail.com

\begin{abstract}
Objective: Both pulmonary and extra pulmonary causes could present as tachypnea and respiratory distress. We have planned a study to evaluate acid base status and outcome of neonatal respiratory distress. Methods: A prospective study carried on neonates admitted in intensive care unit from $1^{\text {st }}$ November 2014 to $31^{\text {st }}$ October 2015 in Department of Paediatrics of a tertiary care centre of UP. Ethical Clearance was taken by Ethics Committee of the college. Newborns brought to our NICU with respiratory distress were included in study randomly. After detailed clinical history, examination, arterial blood was taken in all the babies for ABG analysis with necessary precautions along with other routine investigation and stabilization of the baby. Results: A total of 115 neonates with respiratory distress were selected for study, out of these about $24.34 \%$ had normal pH, $45.21 \%$ had metabolic acidosis, $21.73 \%$ neonates had respiratory acidosis and $8.69 \%$ had mixed $\mathrm{pH}$ disorder. Neonates having respiratory distress with normal $\mathrm{pH} 85.71 \%$ were discharged from the hospital, 7.14\% went LAMA and 7.14\% expired during the treatment. Neonates having respiratory distress with abnormal $\mathrm{pH} 77.01 \%$ were discharged from the hospital, 2.29\% went LAMA and 20.68\% expired during the treatment. Conclusion: The expiry rate was significantly higher in neonates having abnormal $\mathrm{pH}$ with respiratory distress than in neonates with normal $\mathrm{pH}$ with respiratory distress $(\mathrm{p}<0.05)$.
\end{abstract}

Keywords: Neonatal respiratory distress, Acid base abnormality, Meconium aspiration syndrome, Transient tachypnea of newborn.

\section{Introduction}

Neonatal respiratory distress is a heterogeneous group of illness with varying incidence, underlying etiology, clinical course and outcome. It is one of the commonest disorders encountered within the first 48-72 hours of life. It occurs in approximately $0.96 \%-6 \%$ of live births, and is responsible for about $20 \%$ of neonatal mortality [1]. Respiratory distress is a common reason for a neonate seeking medical attention. The clinical features of tachypnea, intercostal retractions, grunting or cyanosis could be the manifestations of a variety of etiological causes. Both pulmonary and extra pulmonary causes could present as tachypnea and respiratory distress [2].

Manuscript received: $12^{\text {th }}$ Dec 2015

Reviewed: $25^{\text {th }}$ Dec 2015

Author Corrected; 04 ${ }^{\text {th }}$ Jan 2016

Accepted for Publication: $13^{\text {th }}$ Jan 2016
Respiratory distress due to either medical or surgical causes occurs commonly in neonates. It is the most common cause of admission to a neonatal surgical intensive care facility in a tertiary care hospital [3]. Blood gas measurements and complementary, noninvasive monitoring techniques provide the clinician with information essential to patient assessment, therapeutic decision making, and prognostication. Blood gas measurements are as important for ill newborns as for other critically ill patients, but rapidly changing physiology, difficult access to arterial and mixed venous sampling sites, and small blood volumes present unique challenges [4].

Considering above facts the present study was planned with aims and objective of 
1. To see incidence of various causes of respiratory distress in newborns

2. To see acid base status of neonates with respiratory distress

3. To see the outcome of abnormal acid base neonates with distress

\section{Material \& Methods}

The present study carried out on neonates admitted in intensive care unit from $1^{\text {st }}$ November 2014 to $31^{\text {st }}$ October 2015 in Department of Paediatrics, M.L.B. Medical College, Jhansi UP. Ethical Clearance was taken by Ethics Committee of the college. Newborns brought to our NICU with one or more of following for more than two hours would be considered to have respiratory distress and included in study-

- Respiratory rate $>60 / \mathrm{min}$

- Respiratory grunting

\section{Results}

A total of 115 neonates admitted in SNCU with respiratory distress were taken in to this study. A total of 115 neonates with respiratory distress were selected for study randomly who met the inclusion criteria. Out of above $85(73.91 \%)$ babies were male and 30(26.08\%) were female. The mode of delivery was normal for 48(41.73\%) babies and Caesarian for $67(58.26 \%)$ babies.

Table I: Distribution of neonates with causes of respiratory distress in relation to gestational age

\begin{tabular}{|c|c|c|c|c|c|c|c|}
\hline Gestational Age & Total & RDS & MAS & TTN & PNM & HIE & Others \\
\hline 28-30Weeks & 8 & 7 & 0 & 0 & 1 & 0 & 0 \\
\hline 30-32Weeks & 4 & 3 & 0 & 0 & 1 & 0 & 0 \\
\hline 32-34Weeks & 20 & 11 & 3 & 3 & 2 & 1 & 0 \\
\hline 34-36Weeks & 30 & 7 & 6 & 5 & 6 & 5 & 1 \\
\hline 36-38Weeks & 40 & 5 & 8 & 8 & 10 & 5 & 4 \\
\hline 38-40Weeks & 11 & 0 & 3 & 4 & 4 & 0 & 0 \\
\hline$>40 W e e k s$ & 2 & 0 & 1 & 1 & 0 & 0 & 0 \\
\hline
\end{tabular}

(RDS- Respiratory distress syndrome, MAS- Meconium Aspiration Syndrome, TTN- Transient Tachypnea of Newborn, PNM- Pneumonia, HIE- Hypoxic Ischemic Encephalopathy)

We observed as shown in Table I that Respiratory distress syndrome is the most common cause of respiratory distress in early gestational age group. In gestational age $28-30 \mathrm{wks}$ Respiratory distress syndrome $87.5 \%$ is the most common cause followed by pneumonia $12.5 \%$. In gestational age $30-32$ wks Respiratory distress syndrome $75 \%$ is the most common cause followed by pneumonia $25 \%$. In gestational age 32-34wks Respiratory distress syndrome $55 \%$ is the most common cause followed by TTN 15\%, MAS 15\%, pneumonia 10\%, and HIE 5\%. In gestational age 34-36wks Respiratory distress syndrome $21.21 \%$ is the most common cause followed by PNM $18.18 \%$, MAS $18.18 \%$, TTN $16.66 \%$, HIE $16.66 \%$, and others $3.33 \%$.

In gestational age 36-38wks PNM 25\% is the most common cause followed by TTN 20\%, MAS 20\%, RDS $12.5 \%$, HIE $5 \%$ and others 10\%.. In gestational age 38-40 weeks PNM and TTN 36.36\% each is the most common cause followed by MAS 27.27\%. In gestational age $>40$ wks we observed that MAS and TTN are the more predominant causes. We have observed that as the gestational age advances TTN and Pneumonia were the common causes while RDS was most commonly seen in lesser gestational age. 
Table II: Incidence of acid base disturbance in neonates with respiratory distress

\begin{tabular}{|l|l|l|l|l|l|l|}
\hline Total & Normal & \multicolumn{2}{|l|}{ Metabolic acidosis } & Respiratory acidosis & Mixed \\
\hline $\mathrm{n}=$ & 28 & $52(45.21 \%)$ & $25(21.73 \%)$ & $10(8.69 \%)$ \\
\cline { 3 - 6 } & $(24.34 \%)$ & $\begin{array}{l}\text { Partially } \\
\text { compensated }\end{array}$ & Uncompensated & $\begin{array}{l}\text { Partially } \\
\text { compensated }\end{array}$ & Uncompensated & \\
\cline { 3 - 5 } & & $29(25.21 \%)$ & $23(20 \%)$ & $11(9.56 \%)$ & $14(12.17 \%)$ & \\
\hline
\end{tabular}

Out of 115 neonates included in the study about 24.34\% had normal pH, $45.21 \%$ had metabolic acidosis, $21.73 \%$ neonates had respiratory acidosis and $8.69 \%$ had mixed $\mathrm{pH}$ disorder. None of them had metabolic and respiratory alkalosis. Neonates with metabolic acidosis again divided into partially compensated and uncompensated. $25.21 \%$ had partially compensated and $20 \%$ uncompensated metabolic acidosis. Neonates with Respiratory acidosis again divided into partially compensated and uncompensated. $9.56 \%$ had partially compensated, $12.17 \%$ uncompensated metabolic acidosis. About $8.69 \%$ had mixed type of $\mathrm{pH}$ disorder. We observed that metabolic acidosis was the most common $\mathrm{pH}$ disorder in newborns with respiratory distress.

Table III: Comparison outcomes of neonates with acid base abnormality and without acid base abnormality with symptoms \& signs of respiratory distress

\begin{tabular}{|l|l|l|l|l|}
\hline & Total & Discharge & LAMA & Expiry \\
\hline Normal $\mathrm{pH}$ & $\mathrm{n}=28(24.34 \%)$ & $24(85.71 \%)$ & $2(7.14 \%)$ & $2(7.14 \%)$ \\
\hline $\begin{array}{l}\text { Abnormal } \\
\mathrm{pH}\end{array}$ & $\mathrm{n}=87(75.65 \%)$ & $67(77.01 \%)$ & $2(2.29 \%)$ & $18(20.68 \%)$ \\
\hline
\end{tabular}

By ABG analysis in the neonates with respiratory distress observed that about $24.34 \%$ had normal $\mathrm{pH}$ and $75.65 \%$ had abnormal $\mathrm{pH}$. Neonates having respiratory distress with normal $\mathrm{pH} 85.71 \%$ discharged from the hospital, $7.14 \%$ went LAMA and $7.14 \%$ expired during the treatment. Neonates having respiratory distress with abnormal $\mathrm{pH} 77.01 \%$ discharged from the hospital, $2.29 \%$ went LAMA and $20.68 \%$ expired during the treatment. The discharge and expiry of neonates with and without normal $\mathrm{pH}$ was statistically significant ( $\mathrm{p}$ value 0.0124 ) by Fisher's exact test.

\section{Discussion}

Respiratory distress in a newborn is a challenging problem. It accounts for significant morbidity and mortality. Respiratory distress in newborn is one of the commonest conditions contributing to $30-40 \%$ of admissions in NICU. Respiratory distress occurs in $2.2 \%$ of all newborns and in almost $60 \%$ of the infants below 1000gms (ELBW infants).Maintaining acid base balance presents a considerable challenge to the neonate[5]

Out of 115 patient included in the study $73.91 \%$ ( 85) are male and $26.09 \%$ (30) females. From this study we observed that there is a male predominance. Male to female ratio is 2.83:1.Lekhvani $\mathrm{S}$ et al [6] also did a study in in 2010 and found the male-to-female ratio was 4.56:1 (41 males to 9 females). Male ratio is greater than female ratio because female fetal lung produces surfactant earlier in gestation than the male fetal lung. Seaborn T et al in 2010[7], Bresson E. et al in 2010[8] also reported similar reason for male and female lung maturation. Santosh $S$ et al in 2013[9] studied that respiratory distress accounts most common cause of all
NICU admissions and preterm babies were more in number with male predominance.

In our study $41.73 \%$ (48) are born by normal vaginal delivery and $58.26 \%$ (67) are born by LSCS. We observed that predominant mode of delivery is LSCS. Jing Liu et al [10] in 2014 conducted a study and stated that cesarean section and male sex are at risk for respiratory distress. We found most common cause for respiratory distress was Respiratory Distress Syndrome about 28.69\%, followed by pneumonia $20.86 \%$.Lekhvani S et al [6] found that acid-base status ismajor pathological disorders in birth asphyxia, bronchopneumonia, sepsis, and diarrhea, but they have included infants also not only neonates as in present study.

Anitha B, Sethi et al [11] in2015 studied the acid base disturbances in sick neonates admitted in NICU and they also found metabolic acidosis was the most common acid base disorder. In our study, we also observed similar findings. 
In our study the neonates having respiratory distress with normal $\mathrm{pH} 85.71 \%$ discharged from the hospital and $7.14 \%$ expired during the treatment as compared to abnormal $\mathrm{pH} 77.01 \%$ discharged from the hospital and $20.68 \%$ expired during the treatment. This is statistically significant with p value 0.0124 by Fisher's exact test. Lekhvani $\mathrm{S}$ et al also found increased mortality in babies with abnormal acid base status.

\section{Conclusions}

We concluded that neonatal respiratory distress is more common in male babies and babies born by caesarian delivery. Most common cause for respiratory distress was Respiratory Distress Syndrome about 28.69\% followed by Pneumonia in $20.86 \%$.As the gestational age advances most common cause for respiratory distress in a neonates was TTN.

Near term neonates most common cause was pneumonia. While in lower gestational ages Respiratory Distress Syndrome was the most common cause. Neonates with respiratory distress had $24.34 \%$ normal $\mathrm{pH}$ and $75.64 \%$ abnormal $\mathrm{pH}$. The expiry rate was significantly higher in neonates having abnormal $\mathrm{pH}$ with respiratory distress than in neonates with normal $\mathrm{pH}$ with respiratory distress $(\mathrm{p}<0.05)$.

\section{References}

1. Neonatal morbidity and mortality: report of the National Neonatal-Perinatal Database. Indian Pediatr. 1997 Nov;34(11):1039-42.

2. Diwakar KK. Clinical approach to Respiratory Distress in Newborn. Indian J Pediatr (Supplementoptimum pulmonary care of neonates) 2003;70: S53 S59.
3. Kumar A, Bhatnagar V. Respiratory distress in neonates. Indian J Pediatr. 2005 May;72(5):425-8.

4. Brouillette RT, Waxman DH. Evaluation of the newborn's blood gas status. National Academy of Clinical Biochemistry. Clin Chem. 1997 Jan;43(1):21521.

5. Quigley R, Baum M. Neonatal acid base balance and disturbances. Semin Perinatol. 2004 Apr;28(2):97-102.

6. Lekhwani S, Shanker V, Gathwala G, Vaswani ND. Acid-base disorders in critically ill neonates. Indian $\mathrm{J}$ Crit Care Med. 2010 Apr;14(2):65-9. doi: 10.4103/0972-5229.68217.

7. Seaborn T, Simard M, Provost PR, Piedboeuf B, Tremblay Y. Sex hormone metabolism in lung development and maturation. Trends Endocrinol Metab. 2010 Dec;21(12):729-38. doi: 10.1016/j.tem.2010.09.001.

8. Bresson E, Seaborn T, Côté M, Cormier G, Provost PR, Piedboeuf B, Tremblay Y. Gene expression profile of androgen modulated genes in the murine fetal developing lung. Reprod Biol Endocrinol. 2010 Jan 8;8:2. doi: 10.1186/1477-7827-8-2.

9. Santosh S, Kushal Kumar K, Adarsha E. A clinical study of respiratory distress in newborn and its outcome. Indian Journal of Neonatal Medicine and Research 2013; 2(1):2-4.

10. Jing Liu. Respiratory Distress Syndrome in Term Neonates: Published online 2014 Mar 1. doi: 10.5152/balkanmedj.2014.8733

11. Anitha B. Sethi et al., IOSR Journal of Dental and Medical Sciences 2015;14(12): 35-38.

\section{How to cite this article?}

Chaudhary GS, KumarV, Chaurasiya O S., Singh M. Evaluation of acid base status and outcome of neonatal respiratory distress.Pediatr Rev: Int J Pediatr Res 2016;3(1):32-35.doi:10.17511/ijpr.2016.i01.07. 